\title{
Cuidado centrado na família e sua aplicação na enfermagem pediátrica
}

\author{
Family-centered care and its application in pediatric nursing \\ Cuidado centrado en la familia y su aplicación en la enfermería pediátrica
}

\author{
Júlia Peres Pinto', Circéa Amália Ribeiro', \\ Myriam Mandetta Pettengill', Maria Magda Ferreira Gomes Balieiro' \\ 'Universidade Federal de São Paulo. Departamento de Enfermagem. São Paulo, SP
}

Submissão: $10 / 10 / 2008$

Aprovação: 2 1/1 1/2009

\section{RESUMO}

O cuidado centrado na família tem representado um desafio para a área da enfermagem, embora os cuidados domiciliares estejam descritos desde os primórdios na história da profissão. A definição dessa abordagem, seus princípios e a discussão da sua aplicação na enfermagem pediátrica estão descritos no texto com o objetivo de refletir acerca das possibilidades de cuidado à família por meio da atenção ao individuo e à unidade familiar. Dentre as diversas áreas, a enfermagem pediátrica vem se destacando com pesquisas e desenvolvimento de pressupostos teóricos.

Descritores: Família; Enfermagem da Família; Enfermagem Pediátrica.

\section{ABSTRACT}

Family-centered care is a challenge for nursing area, although the home care was described in the professional history since its origins. The definition of this approach, its principles and the discussion about its application in pediatric nursing are described in the text aiming to lead to a reflection about the possibilities of family care, by means of attention to the individual and to the family unit. Among the several areas, the pediatric nursing is highlighted with researches and the development of theoretical assumptions.

Key words: Family; Family nursing; Pediatric nursing.

\section{RESUMEN}

El cuidado centrado en la família tiene representado un desafío para el área de enfermería, a pesar de los cuidados domiciliares ya tengan sido descriptos desde sus orígenes en la historia de la profesión. La definición de este abordaje, sus principios y la discusión de su aplicación en la enfermería pediatrica están descriptos en el texto con el objetivo de reflexionar acerca de las posibilidades de cuidado a la familia por medio de atención al individuo y a la unidad familiar. De entre las distintas áreas, la enfermería pediátrica viene destacándose con pesquisas y desarrollo de los presupuestos teóricos.

Descriptores: Família; Enfermería de la família; Enfermería pediátrica.

AUTOR CORRESPONDENTE Júlia Peres Pinto. Escola Paulista de Enfermagem. Rua Napoleão de Barros, 754. Vila Clementino. São Paulo, SP. CEP 04024-002. E-mail: juliaenf@uol.com.br 


\section{CUIDADO CENTRADO NA FAMÍLIA}

Historicamente, a enfermagem é uma das profissões da área da saúde Que mais convive com a família. Esta condição tem gerado, além de pesQuisas, a disseminação, na literatura científica, de temas relacionados à atuação da equipe de enfermagem junto à família, sem, contudo ter provocado mudanças significativas na prática assistencial do enfermeiro.

Assim, esse artigo tem por objetivo descrever a origem do termo cuidado centrado na família, refletir sobre a sua relação com a enfermagem e sobre a sua aplicação na Enfermagem Pediátrica a fim de contribuir com contínuos debates acerca dessa temática.

A construção do termo cuidado centrado na familia teve início em meados de 1969 com o propósito de definir a Qualidade do cuidado prestado no hospital, segundo a visão dos pacientes e suas famílias, e de discutir a autonomia do paciente frente às suas necessidades de saúde ${ }^{(1)}$.

Inicialmente, o termo empregado era medicina centrada no paciente Que evolui para cuidado centrado no paciente. Com a constatação de Que este não descrevia a abordagem pretendida foi incluído o termo familia, em 1990, direcionando a elaboração dos pressupostos atuais do Instituto de Cuidado Centrado na Familia $(\mathrm{ICCF})^{(1)}$. Desde então, surgiu o termo cuidado centrado no paciente e familia, empregado como sinônimo de cuidado centrado na familia, sendo o segundo, mais divulgado na literatura de enfermagem e, por esta razão, adotado neste texto.

A princípio, o ICCF praticava a abordagem centrada na familia no contexto pediátrico. Com o amadurecimento das crianças e o incentivo para Que estas se tornassem participantes do cuidado à sua saúde, e a ampliação da atenção a adultos e idosos, o ICCF começou a praticar o cuidado centrado no paciente e sua família em outros contextos ${ }^{(1)}$.

O termo cuidado centrado no paciente e família surgiu devido à compreensão de Que a família é considerada um elemento fundamental no cuidado de seus membros e o isolamento social é um fator de risco, em especial para os indivíduos mais dependentes como os muito jovens, os mais velhos e aQueles com doença crônica. Assim, é recomendado Que os profissionais incentivem a continuidade da ligação natural Que existe entre a maioria dos pacientes e suas famílias e sua rede de apoio. Por acreditar Que a família exerce influência sobre a saúde do paciente, essa filosofia assistencial a inclui como parceira na melhoria das práticas e do sistema de cuidado ${ }^{(1)}$. O ICCF define esta abordagem de cuidado à saúde como um processo de planejamento, prestação e avaliação baseados em parceria, com benefícios mútuos entre os pacientes, famílias e provedores. É um cuidado destinado a pacientes de todas as idades e pode ser praticado em Qualquer serviço de saúde, por todos os profissionais de saúde ${ }^{(1)}$.

Os pressupostos centrais do cuidado centrado na família são assim apresentados pelo Instituto ${ }^{(1)}$ : dignidade e respeito: os profissionais de saúde ouvem e respeitam as escolhas e perspectivas do paciente e da família; o conhecimento, os valores, as crenças e a cultura do paciente e da família são incorporados ao planejamento e prestação do cuidado; informação compartilhada: os profissionais de saúde comunicam e dividem as informações úteis de maneira completa e imparcial com os pacientes e a família; estes recebem informações acuradas, no momento oportuno, a fim de efetivar sua participação no cuidado e na tomada de decisão; participação: pacientes e famílias são encorajados e apoiados a participarem do cuidado e da tomada de decisão, escolhendo seu nível de atuação; colaboração: pacientes e famílias são incluídos como base de apoio da instituição; os líderes de cuidado a saúde colaboram com os pacientes e família no desenvolvimento, implantação e avaliação das políticas e programas, na facilitação dos cuidados à saúde, na educação profissional e na prestação de cuidado.

$\mathrm{O}$ cuidado centrado na família tem o objetivo de promover a saúde e o bem-estar dos indivíduos e família e restaurar seu controle e dignidade. De acordo com ele, a definição de família é dada pelos seus próprios membros e as ações não se restringem ao corpo biológico, tendo em vista Que o apoio emocional, social e de desenvolvimento são considerados componentes do cuidado à saúde. Embora seja centrado na família, o cuidado não elimina a competência individual de cada membro em relação à tomada de decisão de sua própria saúde ${ }^{(1)}$.

Na enfermagem, a família esteve presente desde o início da profissão Quando os pacientes eram atendidos dentro de suas $\operatorname{casas}^{(2-4)}$. Florence Nightingale já enfatizava a importância da família e do meio ambiente doméstico no cuidado ao doente. Antes de 1990, algumas especialidades, como a enfermagem pediátrica, a enfermagem materno-infantil, a enfermagem em saúde publica e a enfermagem em saúde mental e psiQuiátrica já valorizavam o cuidado à família, com diferenças no enfoque. Família como contexto, como somatório de suas partes e como cliente tem sido os mais comumente observados $^{(4)}$. Esse cuidado tem compreendido a família como sistema ou unidade familiar, acrescentando, aos pressupostos do ICCF, o termo unidade. No entanto, é possível afirmar Que os pressupostos, descritos pelo ICCF, contemplam a visão de unidade, mesmo Que esta não apareça no texto.

Para fundamentar essa visão têm sido utilizados alguns referenciais teóricos. Na literatura o mais difundido é a Teoria Geral dos Sistemas (TGS), adaptada aos sistemas viventes e aplicada na enfermagem da famíliaa ${ }^{(3-6)}$. A família, sob esta visão, é considerada um sistema compreendido como um complexo de elementos em mútua interação, sendo o cuidado de enfermagem focado na unidade familiar e não na soma de suas partes ${ }^{(3,4,6)}$.

Embora as intervenções de enfermagem à família pautadas nesta visão já venham sendo difundidas no meio acadêmico e nas pesQuisas ${ }^{(2)}$, a prática não tem reproduzido os avanços teóricos e de pesquisa ${ }^{(3)}$. Nesse sentido, dois Questionamentos ainda parecem pertinentes: ao atendermos um membro da família estamos cuidando da unidade familiar? Cuidar de um grupo é o mesmo Que cuidar de uma família ${ }^{(7)}$ ?

Buscando responder ao primeiro Questionamento resgatamos um dos conceitos da TGS aplicado à família - "a mudança em um dos membros afeta a todos na família"(2). Com base nisso, podemos afirmar Que Quando atendemos a um de seus membros, a fim de Que atinja o melhor estado de saúde possível, estamos cuidando da família. Porém, se nos fixarmos apenas nesse aspecto não daremos atenção ao todo e ao Que a doença deste membro provoca na organização e funcionamento familiar; tampouco estaremos cuidando dos demais membros da unidade. Estaremos mantendo uma abordagem centrada no paciente ou apenas no aspecto biológico da doença, contrariando os princípios da enfermagem Que propõe uma visão integral do ser humano.

Apesar disso, a enfermeira generalista tende a atuar sob este 
foco de atenção enQuanto as especialistas, na unidade familiar ${ }^{(2)}$. Quando o foco está no individuo como contexto da família ou na família como contexto de um indivíduo, os membros da família são levados em conta apenas em relação ao familiar doente e não frente às suas necessidades e interação ${ }^{(8)}$.

Tendo em vista Que as necessidades da família variam de acordo com a situação, a enfermeira deve estar atenta para avaliar se naQuele momento sua intervenção deve ser voltada ao individuo ou à unidade familiar, ou se é necessário intervir em ambos, pois as abordagens não são excludentes e nem uma é melhor do Que a outra ${ }^{(8)}$.

Respondendo ao segundo Questionamento - cuidar de um grupo é o mesmo que cuidar de uma família - e considerando grupo na perspectiva interacionista, respondemos afirmativamente a essa Questão. Nesta perspectiva, um grupo, assim como uma família pode ser considerado uma coletividade cujos membros agem com vistas a uma ação comum fazendo deles uma unidade de ação. A ação comum ocorre mediante a interpretação dada a uma situação na Qual estão inseridos, gerando uma ação para enfrentá-la ${ }^{(9)}$.

Nesse sentido, a definição de família de Angelo ${ }^{(10)}$ muito contribui para nossa compreensão de família como pessoas em interação.

“... família é um grupo de indivíduos em interação simbólica, chegando às situações com os outros significantes ou grupos de referência, com símbolos, perspectivas, self, mente e habilidade para assumir papéis. Cada indivíduo tem um passado a resgatar para ajudar a definir a situação e cada um possui uma visão de futuro. Os indivíduos dão significado às situações, usando estes instrumentos, às vezes, prestando especial atenção àQueles com Quem interagem, outras vezes, usando algo localizado fora da situação como guia".

Tendo isso em mente, a enfermeira deve conhecer como a família se define e Qual o significado atribuído por ela às situações. A enfermagem da família adota alguns princípios da Biologia da Cognição para afirmar que "os seres humanos produzem diferentes visões para entender os eventos e experiências de suas vidas”(3).

As noções do pós-modernismo, marco teórico aplicado à avaliação da família, propõe o fim de uma única visão de mundo. Utilizando-se disso, a enfermagem da familia reconhece Que há "tantos caminhos para entender e experimentar a doença Quanto existem famílias tendo experiências de doença"(3).

A enfermagem, enQuanto ciência compartilha dos pressupostos adotados pelo ICCF, porém na literatura de enfermagem é enfatizada a visão do todo e a visão interacionista como possibilidade de influenciar as mudanças de comportamento ${ }^{(3,7)}$. No ICCF é destacada a parceria entre pacientes e famílias em todo o sistema de cuidado à saúde, inclusive na formulação de programas e políticas voltadas às necessidades da família.

O pressuposto Que contempla a parceria também aparece na literatura de enfermagem. Neste caso, os parceiros são capazes de se tornar mais competentes por meio do compartilhamento do conhecimento, das habilidades e recursos. Essa visão promove a capacitação e o empoderamento da família, princípios básicos do cuidado centrado na família, Que possibilitam o desenvolvimento do sentido de controle em suas vidas e geram mudanças positivas Que estimulam seus pontos fortes e aptidões ${ }^{(6,11)}$.

No Brasil, há que se destacar o Programa de Saúde da Família (PSF), como uma tentativa de aproximação com os princípios do ICCF. Uma das metas deste programa, Que reorganiza a atenção básica de saúde, é desenvolver a autonomia das famílias na busca de melhoria de suas condições de vida. Desta forma, evidencia a família como objeto de atenção dos profissionais de saúde na área da saúde coletiva, mas também traz à tona discussões sobre as diversas concepções de família e o cuidado de enfermagem a este grupo $^{(2)}$. Porém, se analisarmos os manuais de atenção à saúde, destinados à aplicação desta estratégia observamos Que os mesmos abordam a saúde da criança, do adulto, da mulher e do idoso individualmente, inclusive destinando prontuários individuais dentro de uma pasta da família sem, no entanto, abordar a unidade familiar e a interação entre seus membros. Esta prática traduz a compreensão dos profissionais acerca do Que é cuidar da família em alguns seguimentos da área da saúde.

O sentido do processo de trabalho do PSF é a família como unidade do cuidado. Para o alcance das metas, é necessário Que seja explicitada a definição de família, Que a assistência se volte à experiência da família ao longo do tempo, Que seja dirigida aos membros sadios e doentes, Que considere que o sistema familiar é influenciado por Quaisquer mudanças de seus membros, Que considere os relacionamentos familiares, Que busque focalizar a atenção nas forças da família para promoção de apoio mútuo e crescimento, Que considere os contextos culturais de cada família, o ambiente em Que vive e a comunidade na Qual está inserida e Que haja interação dos profissionais de saúde com a família ${ }^{(12)}$.

\section{CUIDADO CENTRADO NA FAMÍLIA E A ENFERMAGEM PEDIÁTRICA}

Na enfermagem pediátrica, o Cuidado Centrado na Família é uma filosofia Que além de cuidar da criança também reconhece a sua família como unidade de cuidado. Tal definição considera a família como constante na vida da criança e a unidade básica de saúde na Qual a criança receberá os cuidados de promoção à saúde e prevenção de doenças, além dos primeiros atendimentos ${ }^{(13-15)}$. Essas definições englobam pressupostos Que já haviam sido descritos por Shelton et $\mathrm{al}^{(14)}$, em 1987, e Johnson ${ }^{(15)}$, em 1990 propondo os seguintes elementos para o cuidado centrado na família: reconhecer a força da família como uma constante na vida da criança; facilitar a colaboração entre pais e profissionais em todos os níveis de cuidado à saúde; respeitar e valorizar a diversidade cultural, racial, étnica e socioeconômica da família; reconhecer as forças e individualidade da família, respeitando os diferentes métodos de enfrentamento; compartilhar informação imparcial e continuamente com a família; responder às necessidades de desenvolvimento da criança e da família; adotar políticas de praticas Que fornecem apoio emocional e financeiro para família; planejar um cuidado flexível, culturalmente competente e Que responda às necessidades da família; encorajar e facilitar o suporte familiar e da rede apoio.

Houve um avanço na Enfermagem Pediátrica ao incluírem a família como unidade do cuidado. O cuidado centrado na família foi então, definido como a maneira de cuidar da criança e sua família assegurando que haja um planejamento em torno da família como unidade, na Qual todos os membros sejam reconhecidos como

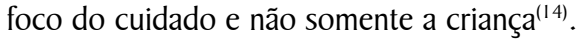

Apesar de elaborados há vinte anos, os pressupostos da abordagem centrada na família, igualmente ainda não são traduzidos na prática da enfermagem pediátrica embora a literatura descreva 
suas vantagens. São elas: o envolvimento da criança e da família nas Questões de saúde, aprendizagem continuada a partir das expectativas da família, relacionamento mais democrático e divisão das responsabilidades entre profissionais e família, maior compromisso da família, ampliação da assistência intra-hospitalar para a comunidade e maior probabilidade de diminuir a necessidade de cuidados institucionais ${ }^{(15)}$.

Desenvolver habilidades que nos possibilite atuar com competência junto à família continua sendo um desafio. Angelo já enfatizava, em 1999, Que "são muitas as dificuldades existentes no caminho daQueles enfermeiros Que se dispõem a abrir-se para a família”(16)
No Brasil, a enfermagem pediátrica vem contribuindo, expressivamente, com pesQuisas Que buscam aprimorar a visão do cuidado centrado na família. No entanto há necessidade de ampliar a inclusão e atualização dos conteúdos referentes à família nos cursos de graduação e pós-graduação, nos serviços de educação continuada, assim como, formar enfermeiras especialistas em família atuando em conjunto com as generalistas.

Acreditamos Que cuidar da família seja uma responsabilidade e compromisso moral do enfermeiro e para tanto é necessário Que haja um ambiente de cuidado Que favoreça o relacionamento entre enfermeiro-família, a fim de construir uma prática Que a ajude no enfrentamento de dificuldades, em especial em situação de doença.

\section{REFERÊNCIAS}

1. Institute For Family-Centered Care. Partnering with patients and families to design a patient-and family-centered health care system: recommendations and promising practices. $2008 \mathrm{apr}$ [cited 2007 jul 5]. Available from: URL: http://www.family centeredcare.org/pdf/PartneringwithPatientsandFamilies.pdf

2. Rocha SMM, Nascimento LC, Lima RAG. Enfermagem pediátrica e a abordagem da família: subsídios para o ensino de graduação. Rev Latino-am Enfermagem 2002; I (5): 709- 14.

3. Wright LM, Leahey M. Enfermeiras e Famílias: um guia para avaliação e intervenção na família. $3^{\text {a. }}$ ed. São Paulo: Roca: 2002.

4. Friedman MM. Family nursing: research, theory and practice. $4^{\text {st }}$ ed. Los Angeles: Appleton \& Lange; 1998.

5. Cerveny CMO. Família e sistema. In: Cerveny CMO. A família como modelo: desconstruindo a patologia. $I^{\mathrm{a}}$ ed. São Paulo: Psy II; 1994. p. 18-32.

6. Murray P. Influências da família na promoção da saúde. In: Honckenberry MI. Wong Fundamentos de Enfermagem pediátrica. $7^{\mathrm{a}}$ ed. Rio de Janeiro: Elsevier; 2006. p.30-54.

7. Elsen I. Desafios da Enfermagem no cuidado à saúde. In: Bub LIR, coordenador. Marcos para a prática de enfermagem com famílias. Florianópolis: Editora da UFSC; 1994. p. 61-77.

8. Wright LM, Leahey M. Trends in nursing of families. J Adv Nurs
1990; (15): 148-54.

9. Haguette TMF. Fundamentos teóricos de algumas metodologias Qualitativas na sociologia. In: Haguette TMF. Metodologia Qualitativa na sociologia. Ia ed. Petrópolis: Vozes; 200 I. p.2447.

10. Angelo M. Com a família em tempos difíceis: uma perspectiva de enfermagem [tese]. São Paulo: Escola de Enfermagem, Universidade de São Paulo; 1997.

1 1. Corlett J, Twycross A. Negotiation of parental roles within familycentred care: review of the research. I Clinical Nurs 2006; (15): 1308-16.

12. Angelo M, Bousso RS. A enfermagem e o Cuidado na Saúde da Família. Manual de enfermagem [serial online] [cited 2003 jun 25]. Available from: http:www.ids-saude.org.br/enfermagem.

13. Winkelstein ML. Perspectiva da enfermagem pediátrica. In: Honckenberry MI. Wong Fundamentos de Enfermagem Pediátrica. 8 $8^{\text {a }}$ ed. Rio de Janeiro: Elsevier; 2006. p.1-21.

14. Shildes L, Pratt I, Hunter J. Family centered care: review of Qualitative studies. I Clinical Nurs 2006; (15): 1317-23.

15. Elsen, I. Assistência à criança hospitalizada: tipos de abordagem e suas implicações para a enfermagem. In: Schimitz EM. A Enfermagem em Pediatria e Puericultura. $2^{\text {a }}$ ed. São Paulo: Atheneu; 2000. p. 169-79. 